\title{
Lazos de Retorno 1
}

\section{Return Links}

\author{
Cristóbal BELDA NAVARRO
}

Universidad de Murcia

cbelda@um.es

Recibido: 23 de noviembre de 2010

Aceptado: 24 de noviembre de 2010

\section{Resumen}

La exposición celebrada en Murcia durante el año 2010 (Deja en mis ojos su mirada) organizada para conmemorar el centenario del nacimiento de Ramón Gaya estuvo destinada a mostrar la importancia concedida por el artista a los maestros del pasado y a recordar la importancia de los grandes museos en su vida y en su obra. Fruto de esa admiración fueron los conocidos Homenajes, pero también los escritos elaborados como consecuencia de sus visitas a los grandes museos europeos, a sus notas de viaje o a sus geniales ensayos. Fuera de aquella exposición quedaron los referidos al Museo de Arte Moderno de Madrid y al de Bellas Artes de Murcia, centros visitados en los años 1933 y 1934, hoy considerados testimonio de las ideas del artista sobre tales instituciones y sobre la gestión museográfica. A ellos se dedica este trabajo.

Palabras clave: Museo de Arte Moderno de Madrid. Museo de Bellas Artes de Murcia. Museografía

\footnotetext{
1 Así definió Ramón Gaya sus impresiones sobre la ciudad de Murcia, cuando, con motivo de las Misiones Pedagógicas, retornó a ella en 1934. Lazos de retorno recogen los sentimientos despertados en el ánimo del pintor al recorrer de nuevo plazas y calles de su ciudad natal y con su visión recuperar antiguas vivencias, impresiones y sueños de juventud y de adolescencia. Esas reflexiones, el ambiente que recuperaba y su actitud ante el futuro Museo Salzillo o el de Bellas Artes constituyen una de las bases sobre las que se construye este trabajo hasta el punto de imponerse su poética evocación a los más convencionales títulos de otros escritos, aquí considerados, como los dos dedicados al Museo de Arte Moderno de Madrid.
} 


\begin{abstract}
The exhibition Let in my Eyes his Look was held in Murcia during the year 2010. Aimed to commemorate the birth centenary of Ramon Gaya, it also showed the importance of masters of the past for Gaya, as well as the key role of great museums in his life and work. This admiration resulted not only in his celebrated "homages", but also in the notes on his visits to the main European museum and trips, as well as his insightful essays. Although not included in the above mentioned exhibition, the ones in the Museum of Modern Art in Madrid and Murcia Fine Arts, visited in the years 1933 and 1934, are now considered evidence of the artist's ideas about such institutions and museum management. This article focuses precisely on these two visits.
\end{abstract}

Keywords: Modern Art Museum Madrid. Museum of Fine Arts Murcia. Museology

La edición de las Obras Completas de Ramón Gaya, publicadas con motivo del centenario de su nacimiento en 2010, ha dado carácter exhaustivo a los escritos del pintor, ya reunidos en anteriores ediciones, hoy vueltos a la luz con la adición de textos que en su día no quedaron incluidos en los volúmenes de Pre-Textos, la editorial valenciana comprometida con la difusión de la obra escrita de un pintor, ya insólito por este motivo en el panorama artístico español contemporáneo.

A través de reflexiones hechas en sus más memorables ensayos, Velázquez, pájaro solitario, Diario de un pintor, Sentimiento de la pintura y Naturalidad del arte, otros muchos escritos han legado a la posteridad la actitud del artista frente al museo y la grandiosa definición del Prado como la Roca Española.

La exposición Deja en mis ojos su mirada, promovida por el Museo del pintor en su localidad natal, por el Ayuntamiento de la ciudad y por la Fundación Cajamurcia dejó constancia de esos sentimientos y de su paso por las mayores pinacotecas del mundo, sentidas más intensamente en la distancia del exilio (a menudo recordadas como generadoras del Homenaje) y fuente primordial para valorar el arte del pasado y la deuda mantenida con maestros, obras y valores siempre asumidos por su eterna y permanente actualidad. Aquellos admirados maestros fueron sus acompañantes en la exposición conmemorativa del centenario mencionado presidido por el monumental Velázquez (Tentaciones de Santo Tomás) procedente de la catedral de Orihuela.

No es ahora el caso de volver a recordar los juicios emitidos sobre el Prado, la Galería de los Uffizi, el Louvre o el Rijksmuseum, ya ampliamente comentados en el texto Esclavos del sentimiento, el estudio introductorio de la exposición citada, con el que se pretendía rendir homenaje al pintor en su centenario y abordar la posi- 
bilidad de situarlo en su contexto histórico, en reflexionar sobre su actitud frente a las artes y a los artistas en el difícil y comprometido mundo de las vanguardias 2 .

Fuera de aquel texto quedaron dos importantes aportaciones al mundo de los museos fechadas entre 1933 y 1934 y, como era de esperar, la actitud del pintor frente a lo que veía no quedaba desligada - no podía quedar desligada - de su impronta personal, de su manera de sentir la historia y de su forma de valorar la pintura y la escultura de su tiempo y del pasado. Su enfrentamiento al Museo de Arte Moderno de Madrid, todavía ubicado en el edificio de Museos y Bibliotecas y la recuperación de la ciudad abandonada, Murcia, llevaron sus pasos a recuperar viejos recuerdos y a encontrarse con los maestros -Salzillo, Sobejano, Rosales - dejados cuando emprendió fuera de su ciudad natal el camino que le llevó desde las vanguardias a su admiración por el pasado.

\section{El Museo de Arte Moderno de Madrid}

La visita al Museo de Arte Moderno tuvo lugar en 1933 y originó dos escritos dedicados a las impresiones causadas por un lugar propicio para conocer las ideas del pintor sobre los museos ${ }^{3}$. Un museo era un mapa, es decir, la expresión artística, física y espiritual de un país, acaso sentida a la manera de Baudelaire, pero al que faltaban demasiados territorios para ofrecer un panorama suficiente de la pintura de los últimos tiempos. Entre las carencias de valores y de fechas, Nonell, Picasso, Juan Gris y Francisco Bores, se presentaban como los grandes e inexplicables ausentes, y esos artistas eran, junto a otros fondos destacados por Gaya, los que marcaban accidentes, relieves, perfiles y costas, maneras de ser y sentimientos de un país colmado de ausencias ${ }^{4}$. El retrato del arte español era, por tanto, incomple-

\footnotetext{
2 El texto Esclavos del sentimiento, arriba mencionado, aborda la importancia del arte de los museos en la vida y en el pensamiento de Ramón Gaya, motivo para remitir al lector a esas páginas y a las sugerencias planteadas por el pintor en sus visitas al Prado, al Louvre, a su participación en el Museo Circulante de las Misiones Pedagógicas y a la importancia que tuvieron todos ellos en su formación y en la forja de sus sentimientos. Vid. Belda Navarro, C. Esclavos del sentimiento, Murcia, Museo Ramón Gaya y fundación Cajamurcia, 2010.

${ }^{3}$ Los dos textos de Ramón Gaya sobre el Museo de Arte Moderno pueden ser consultados en Dennis, N. y Verdejo, I. Ramón Gaya. Obra completa, Valencia, Pre - Textos, 2010, pp. 669 - 674. Reunidos bajo el epígrafe general Otros escritos 1928 - 1996, aparecen introducidos por el dedicado a Francisco Fuentes, fechado en 1928, y seguido por el correspondiente a la República 1933 - 1935, en el que se incluyen las dos referidas a la Visita al Museo de Arte Moderno de 1933.

4 No es extraño el hecho de que el catálogo del Museo de Arte Moderno haya sido el más desatendido de los proyectos referido al arte español de los dos últimos siglos, pues hasta 1985 no se realizó uno que viniera a sustituir al viejo y venerable texto, sucesivamente editado en 1899 y 1900 . Véase Puente, J. De La, Museo del Prado. Casón del Buen Retiro. Pintura del siglo XIX, Madrid, 1985. El prólogo es del desaparecido Alfonso E. Pérez Sánchez.
} 
to y seguía anclado en la filosofía originaria de un museo surgido a iniciativa de diversos artistas, conscientes del prestigio alcanzado por el arte español más reciente, pero cuyos contenidos fueron perfilándose a medida que el proyecto, ya sugerido en 1847, no fue realidad hasta final de ese siglo ${ }^{5}$. Por ello, Ramón Gaya contemplaba un Museo de Arte Moderno definido por criterios que oscilaron entre los valores del clasicismo y las tendencias oficialmente sancionadas por las Exposiciones Nacionales y rubricadas por las academias ${ }^{6}$. Clasicismo, pintura de historia, costumbrismo o realismo eran los estilos dominantes y definían la filosofía de un museo de naturaleza esencialmente conservadora ${ }^{7}$. Pero, por los años en que Ramón Gaya echaba en falta a esos pintores, Juan de la Encina, director del centro entre 1931 y 1936, estaba comprometido con unos cambios pensados para renovar aquellos contenidos demasiado apegados al pasado. Sus ideas de convertirlo en una institución dinámica, igualmente sensible a los logros de las vanguardias, fue tan decisiva como la posibilidad de inspirar otros cambios que facilitaran en el marco de exposiciones temporales una relación con las tendencias internacionales dominantes en Europa ${ }^{8}$. La dirección de Juan de la Encina cambió el rumbo del museo, incluso aportó nuevas ideas sobre su organización interna, basadas en el diseño de innovadores planteamientos museográficos necesitados también de un nuevo proyecto de arquitectura que fuera consecuencia de su apuesta por la modernidad 9 .

\footnotetext{
5 Un preciso panorama del Museo de Arte Moderno puede verse en Jiménez - Blanco Carrillo De Albornoz, M. D. Arte y Estado en la España del siglo XX, Madrid, 1989.

6 En 1915 un Real Decreto establecía que las obras expuestas en el Museo de Arte Moderno habrían de ser de autores españoles.

7 Leyendo las páginas del catálogo de pinturas del Museo del Prado, escritas por Cruzada Villamil (1865) no sólo comprobamos la importancia concedida al concepto de escuela y a la determinación de sus rasgos más significativos, sino también comprendemos la naturaleza de los argumentos preferidos por esas llamadas pinturas contemporáneas que constituyeron el epígrafe final del mismo, identificado como Galería de cuadros contemporáneos pertenecientes al Museo Nacional: paisajes, retrato, pintura de historia y de costumbres fueron el núcleo esencial de la temática preferida por el siglo XIX. Gran parte de esos contenidos, con las innovaciones introducidas a lo largo de los años desde el momento en que el Museo de Arte Moderno abrió sus puertas al público hasta la visita de Gaya en 1933 dejaron constancia de los temas dominantes. Vid. Cruzada Villamil, G. Catálogo Provisional, historial y razonado del Museo Nacional de pinturas, Madrid, en la imprenta de Manuel Galiano, 1865.

8 Jaime Brihuega habla de la primera exposición dedicada a Max Ernst en España (1936), utilizando precisamente una cita de Sánchez Barbudo, y el compromiso de acercamiento español a las vanguardias europeas materializado en la exposición celebrada en París, con título l'Art espagnol contemporain, en la que figuraban obras de Pedro Flores, cuyo catálogo fue prologado por Juan de la Encina y Jean Cassou. Vid. Brihuega, J. Las vanguardias artísticas en España 1909 - 1936, Madrid, 1981, p. 369. La exposición de Max Ernst fue inaugurada el 26 de marzo de 1936 en el Museo de Arte Moderno, todavía situado en el edificio denominado Palacio de Museos y Biblioteca Nacional. En 2009 la Fundación Mapfre volvió a exponer aquellos collages conocidos como semaine de bonté, Fue Paul Eluard el que convenció a Ernst de la conveniencia de la muestra de Madrid, cuyo contenido no sufrió daño alguno, a pesar del clima de inestabilidad social y política que precedió a la guerra civil. 9 Vid. Brihuega, J. "1933. Meridiano crucial de la cultura artística en el Estado Español", 3 ZU, revista d'arquitectura, 4, Barcelona, 1995, pp. 6 - 13.
} 
Pero con los criterios museográficos originarios era lógico que ninguno de los ausentes tuviera acomodo en las salas de un museo configurado con planteamientos artísticos tradicionales, necesariamente transformados por el tiempo para acoger obras contemporáneas, especialmente del siglo XX, a medida que la institución, dependiente del Prado o como entidad autónoma, definiera su posición museológica, perfilara su identidad y acotara sus contenidos hasta quedar convertido en espacio destinado a mostrar los logros de los siglos XIX y XX. Toda la historia posterior no es más que el reflejo de iniciativas y propuestas para dotar al arte español contemporáneo del marco adecuado que, además de establecer fronteras cronológicas precisas entre los fondos propios del Prado y los que deben ser exhibidos en lugares apropiados a tendencias y artistas de nuestro tiempo, diera como resultado la creación de centros como el Reina Sofía en el que se encuentran los ausentes añorados por Gaya en su visita al desaparecido Museo de Arte Moderno en 1933.

A raíz de las ausencias Gaya desveló su interés por Nonell, Picasso, Juan Gris y Bores, entre los pintores contemporáneos, junto a los nombres destacados por obras singulares (Eugenio Lucas, Rosales y Solana), a modo de historia urgente de la pintura española desde Goya hasta su época, mostrando cómo rara vez quedan desvinculadas las reflexiones del pintor sobre aquello que ve, siente y propone de la forma con que una interpretación museológica debe responder necesariamente a los logros de la historia del arte, y más si sus fundamentos metodológicos quedan cosidos a la identidad del museo (Arte Moderno) y a todo cuanto abarcaba un concepto tan impreciso y polémico como el que había adoptado la identidad del término ${ }^{10}$. El concepto de lo moderno había evolucionado, mientras el Museo aún conservaba su vieja atmósfera y esa disparidad no sólo justificaría las ausencias sino también las carencias de otras inspiraciones historiográficas que primaran las líneas de expresión detectadas en la pintura española desde Goya hasta Solana. La azarosa historia del museo no podía quedar desvinculada de sus constantes penurias museológicas tanto más notorias cuanto que lo tardío de su nacimiento siguió pesando sobre su identidad y sobre los verdaderos objetivos de la institución sometida a vaivenes que ponían al descubierto su falta de adaptación al concepto de lo moderno y al peso del arte español en el mundo contemporáneo'11.

\footnotetext{
10 En el catálogo de Joaquín de la Puente (vid. ut supra, p. 88) queda constancia de que el retrato de Josette (1916) de Juan Gris ingresó en el Museo en 1979 como donación de Douglas Cooper al Museo del Prado.

11 Joaquín de la Puente ya destacó el hecho de que el cuadro de Picasso Mujer en azul, de 1901, joya indiscutible del Museo Nacional Centro de Arte Reina Sofía, perdida durante más de cincuenta años, nunca apareciera expuesta en el Museo de Arte Moderno. Vid. Puente, J. de la, Museo del Prado. Casón del Buen Retiro, op. cit, p. 14. Precisamente en esa obra es en la que se ha detectado una cierta proximidad de Picasso a Isidro Nonell haciendo todavía más evidente la pasión que Gaya sintió por ellos y las razones que le avalaban cuando en la famosa exposición de La Pedrera se lamentaba el murciano de haber escrito demasiado sobre Picasso (desasosegado conflicto) y poco sobre Nonell, un agua pic-
} 
¿Qué sentía Gaya por esos nombres? Es sorprendente la selección realizada para calibrar la importancia de los pintores españoles del XIX que estuvieron por encima del gris panorama de un siglo tan poco estimado por el pintor. Independientemente de no encontrar al mejor Goya allí presente, los artistas tenidos en cuenta son valorados por determinadas circunstancias. Eugenio Lucas, no por goyesco sino por su cercanía a Murillo en el famoso Cazador, Eduardo Rosales, como el único pintor de genio y nervio de todo el siglo XIX por medio de un Desnudo (pintado hacia 1869) rebosante de vida, cuya presencia y proximidad se sentía en la solitaria sala del museo, y unas Coristas de Solana que representaban lo más genuino del pintor cuando era capaz de abandonarse a su propia mano.

Las tres obras mencionadas sirven de referencia para transmitir una idea clara de la pintura en su acepción más humana y directa. El Desnudo, la Nicolina representada al salir del baño en Roma, tiene el pudor y la naturalidad ya vistas en la Venus del Espejo de Velázquez12. Que Ramón Gaya afirmara que en la soledad de la sala donde contempló la obra sintiera, sin verla, su proximidad y su presencia, como las obras de Fidias o de Velázquez no es más que la confirmación de unas sensaciones que en su día compartieron Gregorio Prieto, Gaya Nuño o Francisco Bores, uno de los pintores admirados por Gaya ${ }^{13}$.

Los juicios sobre Eugenio Lucas Velázquez fueron, sin duda, una premonición de lo que el pintor había de desvelar a los estudios recientes sobre su personalidad y su obra, lejos de la veta goyesca que le convirtió en un mero imitador del aragonés y provocó una tremenda confusión en la obra de ambos. Ya Calvo Serraller combatió esa tendencia historiográfica de considerar los méritos de Lucas como los de un mero copista de los cuadros de Goya, en detrimento de otras cualidades como la carga expresiva de sus obras, representativas de un costumbrismo de veta brava, "eufemismo que quiere significar no sólo la huella de Goya, sino la de su visión desgarrada y nada complaciente del pueblo", una forma de reaccionar, al decir de Calvo

tórica natural, que fluía natural. Vid. Ramón Gaya, la hora de la pintura, Fundación Caixa Catalunya, Barcelona, catálogo de la exposición celebrada entre 18 de julio al 30 de septiembre de 2006.

12 Años más tarde (Madrid, 1997). Gaya, ante el desnudo de Rosales, comprendió el significado de la modernidad como un tímido y atrevido frescor, que de pronto se aviniera a dar unos pasos. Esa idea le llevó a criticar al arte moderno, absolutamente convencido de vivir permanentemente en una actualidad ingeniosa, más o menos inédita, que se llamaría, un tanto militarmente, "las vanguardias". El cubismo es acaso el "movimiento" más noble, más pictórico de nuestro pobre siglo XX, pues todo lo que viene después - dadaísmo, expresionismo, surrealismo...- no es más que un constante galimatías, falso, artificioso. Completamente inútil, además. Porque la Pintura es siempre ella misma. Nuestro siglo, en cambio, creyó que se trataba, muy afanosamente, de inventar a diestro y siniestro. Ahora, Mujer al salir del baño de Eduardo Rosales, no es que me parezca un cuadro antiguo ni moderno, sino pleno, completo, permanente.

13 Carlos Reyero, en la voz sobre Eduardo Rosales, redactada para la Enciclopedia del Museo del Prado, resume la bibliografía esencial sobre el pintor en la que aparecen las obras de Gregorio Prieto, Juan Chacón o Mateo Revilla, entre los principales artistas y críticos que se mostraron especialmente elogiosos con el Desnudo de Rosales en la línea expresada por Ramón Gaya. 
Serraller, ante la imagen complaciente ofrecida por la visión del viajero romántico europeo que buscaba en España la conservación de lo atávico y ancestral. Ese fuerte expresionismo, ya fue puesto de manifiesto en la exposición celebrada recientemente en el Museo Nacional de Arte de Cataluña ${ }^{14}$.

Esa aproximación establecida por Gaya entre el Cazador de Lucas y la impronta murillesca, muestra cómo supo sentir algunas de las influencias detectadas en la obra del pintor, nacido en 1817, dos años antes de la apertura del Prado, y, por tanto, sensible a las enseñanzas que la pinacoteca ofrecía a los jóvenes artistas del siglo XIX. La mirada de Gaya sobre Lucas detectó uno de los componentes básicos de su formación y la capacidad de la pinacoteca, recién abierta, de convertirse en el objetivo de un peregrinaje no sólo válido a los pintores extranjeros, asiduos visitantes de sus salas, sino también a los nacionales dispuestos a aprender de la pintura del Siglo de Oro los vínculos establecidos con un concepto de la realidad, de la expresión y del naturalismo tan vivo y eficaz como el originado en los lienzos de Velázquez, Murillo o Zurbarán.

En ese mismo año 1933 otros artistas reclamaban una apuesta seria y decidida por la naturaleza. Seguramente podríamos detectar grandes semejanzas entre los alegatos de Gaya a favor de los valores permanentes e irrenunciables en las artes, no encontrados en las vanguardias, y los juicios del fotógrafo Henry CartierBresson publicados a principios de 1934 en Madrid por el periódico Luz en su número del 2 de enero. En el marco de una exposición fotográfica, llamada antigráfica, el arte de la fotografía, había madurado lo suficiente como para ser considerado un elemento subjetivo de la expresión, pero -añadía el autor - la nueva fotografia con ser tan reciente, ha avanzado ya tanto que puede permitirse el lujo de iniciar un ligero "retorno", peculiar a todas las artes o tendencias de vanguardia, tras un primer periodo frenético. Los fotógrafos animistas han hecho ya tantas cabriolas con su cámara, paseándola hacia un arroyo o hacia los tejados, colgándola de

14 La exposición celebrada en Barcelona, en la sede del MNAC, llevó por título El imaginario de Eugenio Lucas. La influencia de Goya en la poética romántica, Barcelona, 4 de noviembre de 2008 a 1 de febrero de 2009. En 1996, en el catálogo de la Fundación Mapfre (Eugenio Lucas Velázquez en La Habana) celebrada en Madrid del 20 de febrero al 21 de abril de 1996, Francisco Calvo Serraller expuso su contrariedad a esa corriente historiográfica que llegó a confundir lo mejor de Goya y de Lucas. En su texto sobre este último, destacó otras influencias de la pintura del Siglo de Oro, como las de Velázquez, Martínez del Mazo, Carreño o Murillo. En su opinión, lo "goyesco" se había convertido en un galimatías peligroso. Vid. Calvo Serraller, F. Eugenio Lucas Velázquez en la colección del Museo Nacional de La Habana, en el catálogo de la exposición citada ut supra, p. 25. Ya el propio José Manuel Arnáiz (Eugenio Lucas. Su vida y su obra, Madrid, 1981) puso las cosas en su sitio, intentando deshacer el problema de atribuciones y tratando de explicar el tremendo lío ocasionado por erróneas asignaciones que fueron en detrimento de la calidad de Eugenio Lucas. Para la reacción a la imagen romántica de España, vid. Calvo Serraller, F. La imagen romántica de España. Arte y arquitectura del siglo XIX, Madrid, 1995. 
un árbol o poniéndola bajo la panza de un automóvil, que bien pueden permitirse el lujo de volver a la simple actitud, ingenua, ante el natural"15.

Solana sirvió para oponer de nuevo su admiración por el pintor, cuando es fiel a sí mismo, a la inconsistencia de algunos fenómenos de la vanguardia. Ésa era, sin duda, la firmeza del Pombo, La Vitrina y Las Coristas frente "al bombón fino, la estampa exquisita" representada por Degas ${ }^{16}$. La ironía de Gaya ante la consideración de ciertos maestros sólo se impuso determinados límites cuando el encausado mostraba a lo largo de su carrera episodios interesantes como Sorolla, Zuloaga, Sunyer, Mir o Rusiñol en una mezcla, difícil de separar, de sus propias inmersiones críticas en la historia de la pintura de su respuesta a la naturaleza de un museo. El carácter vivo de los modelos solanescos, la atmósfera sórdida de las mujeres de la vida, como la palpable realidad de las Coristas y el denso clima de un angosto habitáculo son tan vivos y reales para Gaya, tan llenos de olores intensos, como ciertos y verdaderos fueron los ácidos escritos del autor sobre la realidad española, llena, como diría Goya, de negros presagios ${ }^{17}$. Parece lógico admitir la condescendencia de Gaya por una obra de Ignacio Zuloaga, La Celestina, (1906), aunque despojada de la intensa fuerza expresiva y de la dramática visión del Solana de las Mujeres de la vida o de los inquietantes y enigmáticos maniquíes de Las Vitrinas ${ }^{18}$.

15 Vid. Bonet, J. M. Diccionario de las vanguardias en España (1907 - 1936), Madrid, 1995.

16 López Serrano, R. J. Solana: los personajes en su literatura y en su pintura: una visión simbólica de la vida, Santander, 2004.

17 María José Salazar y Andrés Trapiello dirigieron en el año 2004 una exposición sobre Solana en el Museo Nacional Centro de Arte Reina Sofía. La clasificación temática realizada sirvió no sólo para dar a conocer mejor la obra de este pintor, al que Gaya conoció y trató, sino para desvelar la naturaleza de sus modelos e iconografía. Sobre las Coristas citada por Gaya, entre las obras recordadas tras su paso por el Museo de Arte Moderno, vid. Pérez Amat, R. "Palabra e imagen: análisis de las "Coristas" de Gutiérrez Solana”, Revista de Ciencias de la Información, (Madrid, 1984), pp. 249 - 276.

18 Ramón Gaya se refiere necesariamente a una de las dos versiones de Las vitrinas pintadas en 1910, porque los comentarios de Ramón Gómez de la Serna en su monografía sobre Solana (José Gutiérrez Solana, Buenos Aires, 1944, pp. 53 - 57) en los que cuenta los detalles de esta obra surgida de la contemplación de unas vitrinas realizadas a instancias de D. José Ramón Mélida para que maniquíes de cartón exhibieran trajes de Manolas, Manolos y Marqueses del siglo XVIII en una sala del Museo Arqueológico Nacional, se refieren a la que en ese mismo libro aparecía en poder de Gregorio Marañón. Tanto llamaron la atención del pintor aquellos seres de cartón encerrados en sus vitrinas que solicitó permiso para pintarlos. Cuando los hubo pintado, dice Ramón Gómez de la Serna, les gastó una broma solanesca y pintó un señor de sombrero de copa, tan pequeñín que volvía doble el tamaño de lo que tenía antes un tamaño natural (...) haber sentido el deliquio de esas vitrinas que montó Mélida, uno de los artistas más finos del pasado, revela un alma poética, esa alma poética y de calzonazos que tiene Gutiérrez Solana. Para mi aquello era una señal inconfundible de hallador y quedamos unidos como polilla de la misma vida secreta. La relación entre Las vitrinas y los escritos de Solana ha sido puesto en relación por Arroyo Fernández, M. D. "Realismo, regionalismo y vanguardia en la construcción de la modernidad artística. El Madrid social en la narrativa de José Gutiérrez Solana", Rev. de Ciencias Sociales, 4, (2010), pp. 1-22. 
Gaya añoraba la cercanía de esos pintores ausentes, como también la de otros escultores, cuyas obras estaban cambiando el panorama español. Gargallo realizaba en ese preciso año de 1933 su famoso Profeta. Picasso era la metáfora del genio como antes lo fue Francisco de Goya. El genial baturro se presentaba a los ojos críticos del pintor como el representante de una tradición expresiva cuya continuidad en el siglo XX representaban Isidro Nonell y José Gutiérrez Solana, los únicos dignos de atención.

No hay que perder de vista dos ideas fundamentales, el valor permanente de la modernidad, eso que es y siempre está desde Altamira a Picasso, y los logros del arte de su tiempo como soportes de una reflexión que marcó las líneas de tensión que el arte español había trazado a lo largo del XIX y a las que el pintor murciano fue especialmente sensible como dejó anotado en las páginas del Sentimiento de la pintura.

Pero también otras ausencias llamaron su atención para poner el acento en la necesidad de exponer en un museo algunas de las tendencias más cercanas. Es el caso de Francisco Bores, uno de los pintores adscritos a la Generación del 27, que para Gaya tuvo magistrales destellos desde los recuerdos de París, todavía muy cercanos a los años de estos textos, pues el madrileño, tan relacionado con los ambientes culturales de su ciudad de origen, tenía estudio en aquella ciudad por los años 1927 y 1928, precisamente los recordados por Gaya, cuando fue objeto de atención por parte de la crítica y de la historia que ya dedicó uno de sus primeros trabajos a las obras de esos años en Cahiers d'Art y participó en memorables exposiciones individuales y colectivas en las Tullerías, en el Salón de los Verdaderos Independientes o en la Valentine Gallery de Nueva York ${ }^{19}$. Esas noticias biográficas pueden servir de aclaración a lo que Gaya llama momentito de Bores, pero sobre todo define tanto la importancia del ausente del Museo de Arte Moderno de Madrid como la fama de pintor, imitado, por los años en que se abría camino en París ${ }^{20}$. A partir de 1947 sus obras serían adquiridas por diversos museos franceses, en 1949 lo haría el de Nueva York.

El silencioso Bores que va y viene de España sin ser notado, el admirado artista cuya semblanza brevemente recordó Gaya dos años después (1935), ejemplifica

19 El trabajo de E. Teriade sobre Francisco Bores, al que la crítica se refiere de una forma elogiosa, fue publicado en Cahiers d'Art, 3, (París, 1927). El 1 de agosto de ese mismo año el propio Teriade publicaba un artículo en La Gaceta Literaria de Madrid $\left(\mathrm{n}^{\circ} 15\right)$ con el título Los jóvenes pintores españoles en París: Francisco Bores. Teniendo en cuenta que la revista Cahiers d'art fue fundada en 1926 por Christian Zervos como firme apuesta por las vanguardias, se comprenderá el éxito de Bores al ser objeto de atención por esta tan prestigiosa revista que pronto alcanzó una posición dominante en el mundo del arte. Vid. para ello Grant, K. "Cahiers d'art and the Evolution of Modernist Painting", the Journal of Modern Periodical Studies, no 1, (Pennsylvania, 2010), pp. 216 - 227.

20 Carmona, E. Francisco Bores. El ultraísmo y el ambiente literario madrileño, 1921 - 1925, Catálogo de la exposición celebrada en la Residencia de Estudiantes, 18 - Septiembre al 14 Noviembre, Madrid, 1999. 
la posición personal del murciano frente a la búsqueda incesante de novedades en la pintura por parte de los jóvenes artistas de su generación ${ }^{21}$. El éxito de Bores, su dedicación constante a la creación, las ansias de novedad parecen ser un inconveniente a su propia evolución como artista. Gaya se pregunta si la gran acogida que deparó París a Bores fue un beneficio o significó una desviación de sus juveniles ímpetus. Bores y Gaya aparecen en las páginas de ese texto como dos pintores de diferente identidad, incluso, cuando entre líneas se lee cierto reproche del madrileño a la resistencia del murciano a introducirse en la llamada modernidad, a su incomprensión por el camino seguido, ajeno a la oficialidad de las vanguardias, considerando una actitud egoísta tan incomprensible como la cruzada emprendida por Picasso, Bores o Braque para reconquistar en la sociedad de su tiempo el papel perdido por la pintura.

1933 también vio asomarse a Madrid una exposición sobre arte contemporáneo francés en el Palacio de Museos y Bibliotecas, donde entonces estaba instalado el Museo de Arte Moderno, acompañada por un ciclo de conferencias impartidas en el Instituto Francés sobre las tendencias generales del arte francés contemporáneo y ochos siglos de arte francés. Estas experiencias mostraban el interés suscitado por las conquistas más recientes, especialmente desconocidas las españolas por quedar limitadas a la experiencia de artistas "confinados dentro de sí mismos" como explicaba García Maroto a Juan de la Encina al abogar por otros cauces para la pintura en los que tuvieran cabida artistas a los que no prestaba atención ni la oficialidad colgada de las exposiciones nacionales ni la crítica "de tan pobres destinos" como era la dominante en aquel primer cuarto de siglo $\mathrm{XX}^{22}$. Algunos de aquellos ausentes habían colgado sus obras en el Primer Salón de Artistas Ibéricos, al menos, muchos de los amados y admirados por Gaya, Bores o Moreno villa, entre otros.

La visita de Gaya al Museo de Arte Moderno no quedó circunscrita al mundo de la pintura sino que en un segundo escrito dejó constancia de sus impresiones sobre la escultura. A la lamentada ausencia de Pablo Gargallo siguieron otros clamores sobre la exclusión de Manolo Hugué y Apeles Fenosa, por el que Picasso sentía gran admiración.

\footnotetext{
21 No hay que olvidar que La Gaceta Literaria fue fundada por Ernesto Giménez Caballero en 1927 y que fue una publicación que apostó seriamente por la vanguardia. Aunque la deriva ideológica de la misma fue consecuencia de la ideologización de sus fundadores y redactores, es llamativo el lamento de Gaya por la ausencia de Bores en el Museo de Arte Moderno cuando las revistas contemporáneas habían advertido la importancia de su obra y explicaban, como en el caso de Teriade, la misión de las vanguardias. Vid. Gómez Alfeo, M. V. y García Rodríguez, F. "Descripción y análisis de las críticas de arte publicadas por la Gaceta Literaria", Documentación de Ciencias de la Información, 32, (Madrid, 2009), pp. $25-50$.

22 Vid. Brihuega, J. "García Maroto y la "Nueva España" de 1930 que los españoles leyeron en 1927", Cuaderno de Estudios Manchegos, 19, Ciudad Real, 1989, pp. 263 - 276
} 
En el catálogo de 1899 la escultura no presentaba mayores novedades iconográficas y temáticas que la pintura, pues, como ella, abarcaba un amplio panorama desde el retrato oficial a la mitología y desde las alegorías a la exaltación de ideales románticos, temas pintorescos y de costumbres y todo tipo de representaciones que merecían el beneplácito de las exposiciones nacionales o resultaban significativas como enaltecimiento de los valores patrios 23 . De la lectura de ese catálogo se obtiene un valiosa información sobre el alcance del concepto de "modernidad", así como de la reducida presencia del arte religioso, despojado de su vertiente devocional (sólo aparece reseñado el Cristo Yacente de Agapito Vallmitjana), orientado más bien a motivos de expresividad y de ternura, labrados en mármol o fundidos en bronce, en un país que durante siglos había convertido la escultura en madera policromada en una de sus más valiosas señas de identidad ${ }^{24}$. Las obras reseñadas en ese catálogo vienen a demostrar los cauces artísticos por los que se movió la escultura española presente en este museo, toda relacionada con escultores salidos de las Academias, algunos premiados con la experiencia internacional adquirida en la de Roma o galardonados en los certámenes oficiales. La obra de Juan Figueras, India abrazando el cristianismo, fue expuesta con éxito en la Exposición Universal de París de 186725. El Yacente de Vallmitjana lo fue en la de Viena de 1873 con una copiosa cosecha de elogios y reproches; el San Juan de Dios de Martín Riesco no alcanzó más que una segunda medalla en la Nacional de 1864, mientras el San Francisco curando a los leprosos (1887) de Agustín Querol triunfaba en las de Berlín, Munich y Viena con sonadas distinciones.

No extraña, pues, que la fidelidad mostrada por el museo a los ideales fundacionales, sumamente estrictos en la selección de obras y artistas presentes en sus instalaciones, resultara anacrónico a Gaya, pintor nada sospechoso de alentar rechazos por el pasado sino de promover la presencia de los nuevos valores de un mundo que, aún estimando los logros del XIX, no podía asumir la esclerosis de una colección tan poco representativa de lo que en 1933 representaba la modernidad.

En medio de aquellas ausencias Julio Antonio pareció a Gaya el valor más sólido de todo lo encontrado en el Museo de Arte Moderno, especialmente sus Bustos de Raza, dotados de un latido, algo - anticipaba- que casi nadie sabe y que casi nadie quiere dar 26. Aquella serie de bustos humildes, de apasionados del dolor,

23 Vid. Reyero, C. Escultura, Museo y Estado en la España del siglo XIX. Historia, significado y catálogo de la colección nacional de escultura moderna, 1856-1906, Alicante, Fundación Capa, 2002.

${ }^{24}$ De las setenta y seis esculturas catalogadas en 1899 sólo ocho presentan iconografía religiosa, labradas en mármol, excepto el San Jerónimo recostado en un peñasco de José Piquer, fundida en bronce. 25 Sobre la india abrazando el cristianismo, vid., Reyero, C. "Pasivos, exóticos, vencidos, victimas. El indígena americano en la cultura oficial española del siglo XIX", Revista de Indias, vol. LXIV, núm. 232, Sevilla, 2004, pp. 721-748,

${ }^{26}$ Los Bustos de la Raza son alegorías de tipos y modelos populares identificados como Gitana María, querida que fue del Pernales, Avila de los Caballeros, Gitana Rosa María, el Minero y la Minera, el Hombre de la Mancha, el Cabrero de Zamora, el Ventero del Peñalsordo, la Mujer de Castilla, el 
bustos que llevan en sus facciones duras toda la tragedia de la belleza, tan admirados por Margarita Nelken, eran el símbolo de todo un pueblo y el compendio de sus caracteres y temperamentos ${ }^{27}$. Esa fuerte impresión, síntesis de la tradición mediterránea y de la austeridad castellana, como sugiriera Margarita Nelken, eran el reverso de las tendencias dominantes por los años en que Gaya escribía sus impresiones sobre Julio Antonio 28 . Los escultores de su tiempo ya eran incapaces de dar ese aliento de vida a sus obras, porque fueron asaltados por una epidemia intelectualista grave que ha provocado todas esas frases de párvulos que tanto se oyen repiquetear: "escultura de peso", "escultura de bulto", "asepsia", "escultura pura", para luego confundir todo esto tan elemental y descontado con la hinchazón 29.

Victorio Macho, Juan Cristóbal, Clará y Adsuara formaron un grupo de escultores poco estimados frente al valor fino y sensible de Ángel Ferrant, no bien representado en el Museo. El balance de la escultura vista no es menos desalentador que el de la pintura. Afectación, banalidad, gorgorito fácil, son las expresiones finales de una visión crítica del museo, signo indiscutible de que el sufrimiento del arte ha sido cambiado por la desgana y la comodidad.

\section{La vuelta a Murcia en 1934. Lazos de retorno}

Las impresiones del viaje a Murcia fueron el resultado de su reencuentro con la tierra de origen, con los lugares y personajes más queridos, tan íntimamente unidos a su vida y a su formación. No extraña la forma con que esas evocaciones aparecieron unidas bajo un mismo nombre, Lazos de retorno, términos con los que quiso expresar la vinculación y el contacto nunca perdidos con la ciudad polvorienta dejada, ni con las tierras, la huerta, los personajes y los iconos gráficos y sentimentales de la historia del pasado y del presente ${ }^{30}$.

Novicio, el Poeta. Entre 1903 - 1905 realizó Julio Antonio en Murcia el busto de Juan de la Cierva.

27 Vid. Pérez Rojas, J. y García Castellón, M. El siglo XX: persistencias y rupturas, Madrid, 1994, pp. 83 - 84. En esas páginas se reproduce la crítica certera de Margarita Nelken, impresionada por la expresividad de la serie de Julio Antonio.

28 Vid. García Rodríguez, F. y Gómez Alfeo, M. V. "Margarita Nelken y el Fígaro", Historia y Comunicación Social, 5, ( Madrid, 2000), pp. 115 - 143.

29 En las Obras Completas editadas en 2010 por la editorial Pre - Textos de Valencia, ya mencionada, se puede consultar toda la cita completa en la que Gaya revela su admiración por Julio Antonio. Incluso hay una referencia a la forma triste con que murió el escultor. Es cierto que Julio Antonio, hombre dotado de una tremenda vitalidad, fue profeta de su propia muerte, sentida muy de cerca por sus amigos, especialmente por Gregorio Marañón, Ramón Gómez de la Serna, Ramón Pérez de Ayala y muchos otros más. Para este último aspecto, vid. Gómez Alfeo, M. V. y García Rodríguez, F. "Documentación y análisis de las críticas de arte sobre el escultor Julio Antonio, el "amado de la crítica”, Documentación de Ciencias de la Información, 27, (Madrid, 2004), pp. 75 - 96.

30 Los textos referidos a ese viaje a Murcia en 1934, reproducidos en este trabajo pueden ser consultados en las páginas correspondientes a Otros escritos , pp. 678 - 693. Por esos años también escribió sobre sus amigos murcianos Juan Guerrero, Luis Garay, Sofía Morales y Raimundo de los Reyes. 
La visión que Gaya trajo a Murcia, cuando en 1934 hubo de visitarla con motivo de las Misiones pedagógicas, estuvo llena de amor y de ternura, tan fuertemente expresada con el término que unió y dio forma a esos recuerdos - enlazó pasado y presente, nunca disueltas las raíces que los vinculaban, que unían su vida y su tierra - que pronto decidió buscar las fuentes en que se nutrían sus recuerdos. Esas poéticas imágenes ahora surgidas de las páginas dedicadas a volver sus pasos hacia el Malecón, plaza de Belluga, Museo Salzillo o de Bellas Artes, revelan con pasmosa madurez la solidez de sus conocimientos, ya forjadas sus ideas al amparo de los grandes maestros gracias al baño de sensatez experimentado en los museos del Louvre y del Prado.

Muchos escritos de Ramón Gaya sobre su ciudad, incluidos en el Balcón español aparecen ya esbozados en los que redactó en 1934, incluso muchos de los que dedicó al Prado ya se encuentran formulados en sus rasgos generales. Por eso, no es de extrañar que la atención prestada a obras y artistas sean los que posteriormente ensalzaría tanto en las impresiones de viajero, como en el Diario de un pintor, en el Velázquez, pájaro solitario, o en los surgidos a raíz de diferentes viajes en los que se enfrentó a una realidad viva y real muy diferente a la sugerida por la nostálgica postal.

El Museo de Bellas Artes de Murcia fue una de las primeras visitas giradas por el pintor para encontrarse con las obras que más le habían impresionado durante su infancia y adolescencia. Seguramente lo que más sobresaltó su ánimo no fue la gris existencia del edificio de Pedro Cerdán, metáfora del esfuerzo de una sociedad que auspició su construcción para evitar la pérdida de tanto patrimonio desamortizado y disperso, sino la disposición museográfica heredada y conservada por su director D. Pedro Sánchez Picazo ${ }^{31}$.

El viejo museo, que con diversas remodelaciones internas no cambiaría de imagen hasta fechas recientes, había sido levantado en los primeros años del siglo XX sobre el solar del desparecido convento de la Trinidad ${ }^{32}$. Precisamente el año en que Gaya nació (1910) era inaugurado el edificio llamado a suplir las carencias de las anteriores instalaciones y a dotarlo de unos componentes espaciales pensados para albergar en pasmosa vecindad diferentes objetos puestos a la consideración del visitante como si del gabinete de un coleccionista se tratara. La posibilidad de acumular distintas obras y de llenar los espacios sin más criterio que el meramente acumu-

31 Aunque la historia del Museo de Bellas Artes de Murcia puede conocerse por la monografía de Martínez Calvo, J. (Historia y guía del Museo de Murcia. Sección Bellas Artes, Murcia, 1986), la edición del catálogo oficial de Museo (el Museo de Bellas Artes de Murcia. La colección permanente, Murcia, 2005) incluye fotografías de las antiguas salas correspondientes a la década de 1930, reproduciendo con gran fidelidad el aspecto que ofreció a 'Ramón Gaya en los momentos de su agria polémica con D. Pedro Sánchez Picazo, director del centro cuando el pintor lo visitó en 1934.

32 La remodelación del viejo museo fue llevada a cabo entre los años 2000 - 2005, afectando a la organización del edificio y a la sistematización de sus colecciones. 
lativo se superponía a unos criterios esenciales, los propios de la fundación de este tipo de museos en el siglo XIX, como un escaparate de las artes de la localidad para consideración del visitante que, de esa forma, adivinaba o creía adivinar, cuál fue el desarrollo de las artes en su localidad y entorno.

En ese contexto, que primaba abundancia frente calidad, el criterio selectivo no era precisamente la metodología más destacada, dada la impronta que todavía el museo tenía de sus precedentes en el coleccionismo ilustrado y en la necesidad de acoger un porcentaje elevado de obras a veces en conflicto con la capacidad de los espacios y de los ojos para asimilar y discernir todo cuanto se le mostraba.

Esa peregrinación por sus recuerdos dejó páginas dedicadas a reflejar las impresiones producidas por la Entrada en Murcia, y la evocación de otras presencias asociadas al polvo de primavera de la ciudad, a su Ángel más famoso y al santuario del arte local levantado en el Museo de Bellas Artes, sentido como nunca en las obras de José María Sobejano, Gil Montijano, Rafael Tegeo o Eduardo Rosales, a quien dedicó un hermoso comentario sobre un llamado dibujo sentimental que no era más que la imagen de la Virgen de la Fuensanta, pintada en medio del entusiasmo sentido por la momentánea mejoría del pintor convaleciente en los aires secos y limpios de la serranía de la Fuensanta ${ }^{33}$.

El lazo iniciador de la serie revive viejos recuerdos en las calles polvorientas, casas y plazas, tapias y una huerta silenciosa que siempre espera ${ }^{34}$. Ese pórtico dio paso al Ángel polvoriento, metáfora de la ciudad y de Salzillo, a modo de una visión poética y personal al recorrer la plaza de Belluga y valorar esa caricia blanca como lluvia leve que es el polvo descansando sobre el imafronte catedralicio y el Palacio episcopal.

El itinerario seguido era, en cierto modo, sugerido por los hitos urbanos más solemnes y monumentales de una ciudad recostada indolentemente junto al río y protegida de sus desastrosas avenidas por el Malecón, como bien sabía el pintor. Desde allí, el tórrido sol de la siesta quedó aliviado por el amparo de las viejas torres de San Antolín, hoy desaparecidas, como una invitación para volver a contemplar a Salzillo. Con este peso de luz, - dice Gaya - cautivo de la siesta, encontré una cúpula en lo lejos donde asirme y dos torres (iglesia de San Antolín) que me aliviaron la mañana. Eran como una promesa de mar azul. Eran tres tulipanes hacia abajo que adornaban la hora de ternura

\footnotetext{
33 Fue precisamente el Museo Ramón Gaya, consciente del interés que Rosales siempre despertó en la vida de Gaya y la vinculación tan especial del artista madrileño con la ciudad de Murcia, el que editó, en colaboración con el Ayuntamiento y Cajamurcia, dos publicaciones dedicadas al mismo, el catálogo de la exposición Eduardo Rosales en Murcia y otros cuadros (entre 17 de diciembre de 1998 y 14 de febrero de 1999) y la monografía de López Delgado, J. A. Eduardo Rosales en Murcia, Murcia, 1999.

34 Cada uno de los textos correspondientes a la estancia en Murcia durante 1934 lleva de forma individual un título determinado, aunque todos se encuentran agrupados bajo la misma identidad sugerida por el término lazo al que acompaña el numeral correspondiente dentro de la misma serie.
} 
El descenso del Malecón, era como entrar por una calle como un pasillo. En la iglesia de Jesús, encontró a Salzillo en su encierro preso, porque la mañana es su sitio, su sala propia, su museo. Las figuras de Salzillo necesitan de cómplices, la vida en torno, Murcia en torno, la luz más polvorienta cogiéndoles de la cintura ${ }^{35}$.

Desde allí al Museo de Bellas Artes. Como un personaje de ficción, Fernando, el eterno conserje, le pareció la reencarnación de D. Antonio el Inglés de Velázquez, el personaje indispensable, nacido y vivido a la sombra de un lugar, el Museo de la Trinidad, llegado hasta allí, creo que desde los días de las desamortizaciones. Nadie sería capaz de decir qué hubiera sido del museo sin la figura de ese guardián fiel. No creo que nadie recuerde sus apellidos, sólo que se llamaba Fernando, asiduo colaborador, guardaespaldas de la pintura, guía gruñón, a cuya casa se accedía por medio de las venerables puertas del Contraste de la Seda, cuando Alejandro heredó de su padre la misión de proteger el legado y custodia de aquel importante patrimonio.

Las salas recorridas facilitaron a Gaya las primeras reflexiones sobre la visión del museo como un extraño traje, de un aire especial, de un fresco encerrado. Museo es buhardilla limpia, desván de lujo.

Inmediatamente se dejó llevar por la acumulación de objetos que presentaba el centro. No era una visita normal, formaba parte de la recuperación de su propia memoria y la posibilidad de encontrarse a sí mismo reflejado en los viejos cuadros admirados. Pronto, su valoración de los espacios, los lugares, las raíces museográficas esperadas se alejaron de la realidad soñada y se volcó, desconsolada, sobre un mundo inesperado muy diferente al que en el recuerdo y la distancia habían quedado siempre asociados a su memoria. Gaya fue buscando una ciudad familiar por sus gentes, sus luces, su polvo de primavera, sus calles, sus huertos y sus monumentos, también por los museos en los que podía valorar la importancia de la pintura y que ésta fuera compartida con los lugares y espacios reservados para sus cuadros más memorables. En el caso de la iglesia de Jesús, cuando todavía no era Museo Salzillo (aunque como tal se consideraba su espaciosa planta) no pudo desvincular la naturaleza devocional de las esculturas ubicadas en los espacios destinados desde su ori-

35 El texto de Ramón Gaya alude a uno de los sentimientos fundamentales de la escultura procesional española, cuyo verdadero sentido se alcanza al fundirse en la oscuridad de la noche o en la luminosidad de una mañana acaricida por el sol del Mediterráneo. Gaya evocaba con esta reflexión no sólo el verdadero significado de una escultura hecha para la calle, para ser contemplada en movimiento, para ofrecerse a los ojos del visitante con formas nítidas y seguras en la claridad del día o confundidas con las sombras de la noche, sino para sentir, como sus contemporáneos, la fascinación por un arte del que no acertamos a comprender dónde está la frontera entre lo real y lo imaginado. Evidentemente, Ramón Gaya contempló la iglesia de Jesús cuando aún no era realidad el Museo Salzillo, creado en 1941, y, por lo tanto, anterior a la remodelación que ha dejado actualmente bien visibles sus valores escenográficos. Avatares, episodios significativos, remodelaciones e historia del Museo Salzillo de Murcia puede consultarse en Torres Fontes, J, EL Museo Salzillo (Murcia), Madrid, Dirección General de Bellas Artes, 1959; Marín Torres, M. T. El Museo Salzillo de Murcia, Murcia, Real Academia Alfonso X el Sabio, 1998. 
gen a ofrecerse a la piedad de los cofrades del paseo cíclico y ritual por las calles de la ciudad. Pero en el de Bellas Artes, concebido como paradigma de la cultura visual propia, había que establecer el rango de cada pintura y la posibilidad de implantar jerarquías que tuvieran en cuenta la personalidad de sus autores y los logros de sus obras. Para un pintor que siempre asoció su primer recuerdo de Murcia a la rama de un frutal, que convirtió los objetos más modestos (copa, cristal, cerámica popular) en señal inequívoca de su mística personal, el matiz, aquello que singularizaba y distinguía las cosas banales de las trascendentes, venía a resultar decisivo si se aplicaba correctamente a criterios pensados para establecer jerarquías internas y para reservar los más luminosos y amplios espacios a las obras importantes y no dejarlas al albur de un visitante avispado, capaz de valorar aquello que el museo ignoraba.

Y surgió la crítica, una crítica feroz a un concepto museográfico poco dado a resaltar los grandes valores de la pintura, de colocarlos en lugares inadecuados como recordara Federico Balart, un paisano de Gaya, nacido en el siglo XIX cuando el Museo del Prado no había definido aún su propia imagen y presentaba deficiencias similares. La Entrada de los Reyes Católicos en Murcia, el Viático en el Huerta, el Retrato de familia, de Rafael Tegeo, el Puente de las Artes de Antonio Meseguer, suscitaron las emociones del reencuentro con las pinturas amadas y la crítica a la vecindad con que estas obras eminentes se mostraban junto a otras de dudosa calidad o poco estimadas por el pintor. Los textos dedicados a esa experiencia murciana son ya páginas construidas en los términos más limpios de la crítica y de la reflexión histórica para mostrar cuál era, en su opinión, el lugar que los pintores habían de ocupar en la historia. José María Soberano, y su admirable obra Mientras rule no es chamba, le pareció un pintor imprescindible, representado por un cuadro espléndido, primitivo, nada ingenuo, aunque candoroso 36 .

Se trataba de un cuadro muy admirado por Gaya, cuyo entusiasmo compartió con sus mentores murcianos Luis Garay, Pedro Flores y Clemente Cantos, así proclamado en una entrevista concedida a Pedro Soler (Diario La Verdad, 1977) y reproducida en el libro editado por Nigel Dennis ${ }^{37}$. Gaya lamentó que el mejor cuadro pintado en Murcia no tuviera el reconocimiento merecido ni un lugar destacado en el museo. Esa valoración, precedida por el entusiasmo sentido por las cosas de Murcia, reavivó sus recuerdos de niño y acabó convertido en un canto de admi-

\footnotetext{
36 El cuadro de José María Sobejano (1852 - 1918), pintado en 1875, va mucho más allá de los horizontes costumbristas a los que pudiera remitir la escena huertana del juego de bolos. En una superficie de 29 x $44 \mathrm{~cm}$. el pintor dejó escrita una página admirable de la vida local y una lección de pintura y de recursos compositivos tan intensos en la distribución de las figuras, en sus actitudes espontáneas y, sobre todo, en la naturalidad con que son captados los comportamientos, los gestos, el movimiento de manos, el arabesco de sus siluetas, y la húmeda frescura de la huerta, que no extraña la admiración sentida por aquellos pintores. Gaya prometió dedicarle un comentario independiente.

37 Vid. Dennis, N. Ramón Gaya. De viva voz, Valencia, Pretextos, 2007, p. 21.
} 
ración a Murcia más dramático, si cabe, al ver el poco afecto mostrado por el Museo hacia el cuadro de Sobejano, del que, dice, haber pintado un homenaje 38.

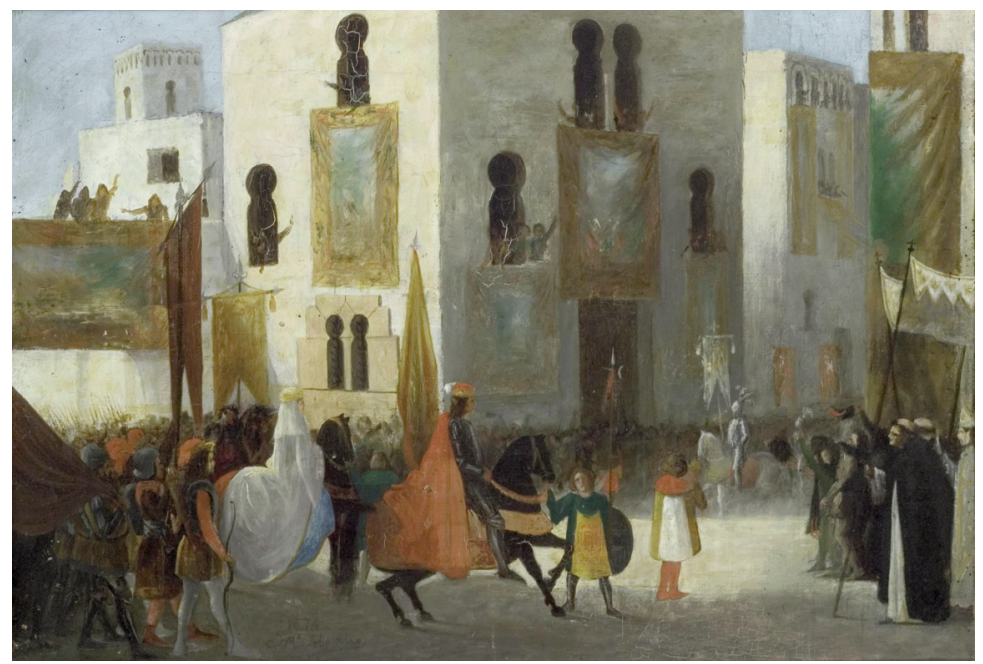

José María Sobejano, Entrada de los Reyes Católicos en Murcia

Gaya reprendió la falta de criterios museográficos claros y bien estructurados que reservaran para las mejores obras lugares de honor. La yuxtaposición, la falta de fundamentos históricos y la ausencia de argumentos artísticos que justificaran y dieran sentido a los movimientos pictóricos más cercanos y conocidos, relacionados por afinidades de estilo o similitudes temáticas, no eran lo más importante para un pintor tan receloso de la historia o, como él mismo aseguraba, de su afán registrador, sino el insulto al buen gusto y a la esencia de un museo concebido como escaparate de lo mejor, como síntesis de la pintura, entendido, en sus propias palabras, como desván de lujo. Ésa era la mayor de las afrentas sufridas, la inadecuada colocación de los cuadros de Sobejano (Entrada de los Reyes Católicos a Murcia) y Gil Montijano (Viático en la huerta) frente a la situación privilegiada de uno de Julián Alcaraz, fue el motivo merecedor de una airada respuesta por situar en lugar preferente una detestable pieza de escaparate, apta para regalo de baile de máscaras $^{39}$. Esa ausencia de principios vertebradores y de argumentaciones que primaran

${ }^{38}$ Efectivamente, el cuadro de Gaya Homenaje a Murcia, propiedad de la Caja de Ahorros de Murcia, es una síntesis del cuadro de Sobejano, cuyos actores son fácilmente reconocibles, de las Hilanderas de Velázquez y de los temas murcianos de Rosales, como la Venta de novillos. Es una declaración del afecto sentido por estos pintores, unidos a través de una escena como la de Sobejano tan importante en sus recuerdos

39 José María Sobejano, pintó en 1874 el cuadro de asunto histórico Tanto monta con destino a la Real Sociedad Económica de Amigos del País de Murcia. La obra que, bajo el título Entrada de los Reyes 
la calidad y la excelencia frente al número, venía, además, avalada por la falta de luz y por la incomodidad de un emplazamiento - la pared de una escalera - a la que el visitante no prestaba más atención que la ocasionalmente merecida por sus complementos decorativos por suponer que, tras la fatigosa ascensión hacia las salas superiores del museo, se mostraría lo más interesante ${ }^{40}$.

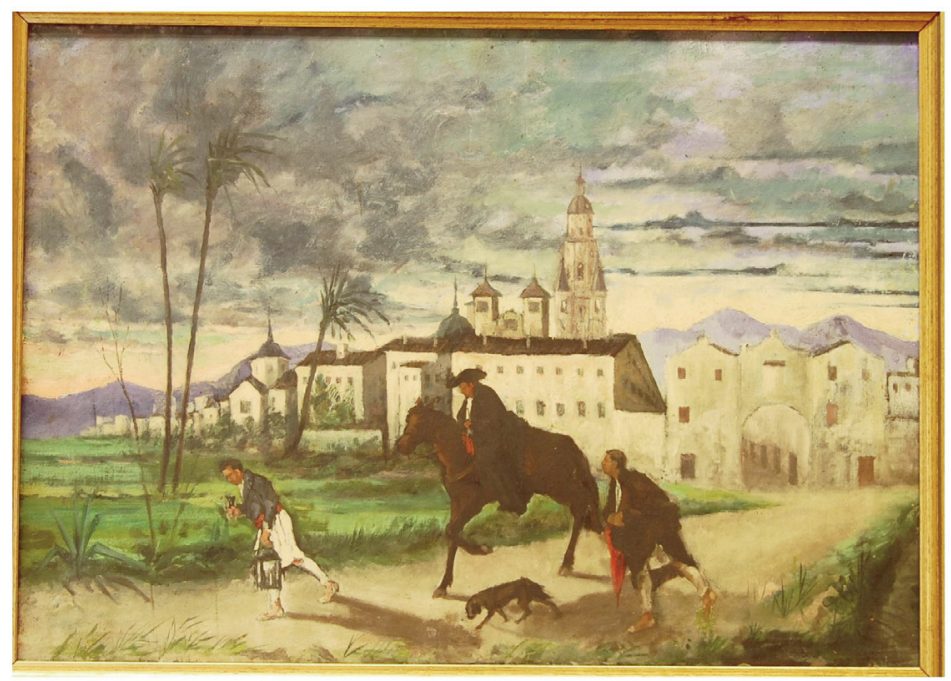

Gil Montijano, Viático en la huerta

Las críticas a otras obras expuestas (Sombrero de copa con polluelos de Alejandro Séiquer) se fueron entremezclando con las dirigidas a D. Pedro Sánchez Picazo, sustituto desde 1922 de ese Séiquer inmortalizado por sus polluelos. Pronto la mordacidad del pintor fue transitando desde la museografía a la persona de su director y, como consecuencia, a la insólita concepción museística de aquel centro. El texto y su conclusión no pudieron ser más demoledores: Un hombre capaz de confundirlo todo con una polvera y convertir el mundo en objetos de tocador de viuda es el caso más deprimente, más inmoral y malsano. Aunque Gaya creyó que sus pensamientos encontrarían la adhesión deseada, la respuesta del director no se hizo esperar. Aqui Picazo, - escribirá Gaya - a quien estimo en mi recuerdo de una forma que él no comprenderá nunca, es decir, como se estima todo aquello que se

Católicos a Murcia, admiró Ramón Gaya era el boceto de ese cuadro, merecedor del premio de los Juegos Florales de ese 1874. Vid. el Museo de Bellas Artes de Murcia. La colección permanente, Murcia, Comunidad Autónoma de la Región de Murcia, 2005, p. 275. Con gran ironía Gaya calificaba los toros de Julián Alcaraz como cartel de fiestas, por lo que sugería que su lugar idóneo debería ser el despacho del charlista valenciano Federico García Sanchís más que las salas de un museo.

40 Las obras de Sobejano y de Gil Montijano se encontraban, según las vio Gaya, bajo una luz pobre y falta de espacio de un muro de escalera. 
vivió en los primeros años; igual que amo esa rama de nisperero que es mi visión más antigua, más lejana, puesto que data de esa época de nuestra niñez en que aún no se ha comprendido con claridad lo que significa agua, casa, traje, y, sin embargo., ya estamos metidos en estas cosas, y hasta se sirve uno de ellas. A quien estimo pero condeno, sin mejor ni peor, sino por esa falta de sinceridad y nobleza. De esta forma, sus cuadros son cromos de comedor cursi.

Hay que entender los puntos de partida desde los que Gaya enjuiciaba al Museo de Bellas Artes de Murcia. La institución se presentaba como la única opción posible a una ciudad, rural y provinciana, de conservar su patrimonio arqueológico y artístico en medio de un clima denso poco favorecedor, como en otros museos españoles, de las condiciones espaciales, de contenido y de sentido histórico, de lógica y atmósfera propia asociada a fondos tan diversos como los que acogió aquel depósito trashumante de viejos jirones del pasado.

Gaya regresaba a su ciudad arropado por un bagaje de lienzos sagazmente seleccionados por Bartolomé Cossío para las Misiones Pedagógicas y dispuesto a enseñar las grandes obras de Velázquez, del que tenía redactado un primer ensayo. Pedro Berruguete, El Greco, Alonso Sánchez Coello, Ribera, Zurbarán o Goya, procedentes del Museo del Prado y debidamente copiados para ser mostrados junto a la literatura, la música o el cine a generaciones de analfabetos que nunca había tenido la oportunidad de recibir una elemental educación, eran los nombres paseados por la geografía española más deprimida. Y aunque Gaya nunca se mostró favorable a aceptar el sentido pedagógico de los museos, ni a reconocer la virtualidad del concepto de escuela, sí era consciente del valor educativo de la pintura y del fervor misionero con que había de ser mostrada para rescatar de la ignorancia a generaciones de labriegos, analfabetos y atrasados, sumidos en el más profundo abismo de una miseria cultural llamada a ser redimida por aquellas embajadas,

Estar en sintonía con esos maestros era lo más importante y, por ello, dotar a los museos de ese elemento liberalizador impulsado por la honesta sinceridad de la pintura valía más que cualquier otro propósito. La emotiva simplicidad del Viático en la Huerta de Juan Antonio Gil Montijano, donado a la Comisión de Monumentos por su autor, sirvió de motivo para ensalzar una de las pinturas más conmovedoras de las existentes en el museo mientras la frescura goyesca del Retrato de familia de Rafael Tegeo, hacen pensar a Ramón Gaya que la pintura española siempre fue romántica. Y eso que la tela de Tegeo no pertenecía a los recuerdos de infancia del pintor. Era un feliz descubrimiento en aquella visita, ya que la Junta de Patronato la había adquirido en 1928, cuando Gaya andaba por París y sufría la primera decepción de las vanguardias.

Curado de esa enfermedad ya venía el pintor dispuesto a probar su fe en el arte del pasado como una de las razones más sólidas de su permanente actualidad y de su instinto moderno. Por ello, no sorprende el encuentro con El Puente de las Artes 
de Antonio Meseguer, merecedor de una amplia disertación sobre la honestidad de la pintura y una ingeniosa comparación con ese implacable seguimiento que los impresionistas hicieron de la naturaleza no para dejarla fluir en sus lienzos sino para registrar sus cambios. Por eso este cuadro, que está hecho en la época y en el país de los impresionistas, es lo opuesto a un Pisarro, a un Sisley, a un Monet, ya que ellos lo que hacen es olvidar lo que "saben" para recoger lo que "ven". El valor de lo ingenuo, viva imagen de su autor, se traslada a un estado de inocencia que debió ser propio del mundo antes del pecado. Y éste - se pregunta - ¿no es el camino que conduce a un Fray Angélico?

Las críticas, por tanto, van dirigidas a la falta de criterios de selección, punto de vista que revela la actitud de Gaya ante los museos a través de ese texto dedicado al de Murcia como al que precede dedicado al de Arte Moderno de Madrid. En muchas ocasiones mostró su discrepancia de los criterios museográficos habituales, de la sincronización histórica y del valor de las escuelas. Gaya mostró, por el contrario, un concepto de museo muy diferente a aquel que lo elevaba a la condición de centro docente sin más, sometido a las directrices de la historia, y de las artes ordenadas por conceptos cronológicos, de escuela y de evolución personal de cada artista. Pero, además, la esclerosis museográfica padecida por algunos centros, que no prestaban atención a los cambios producidos en las obras de los pintores presentes en sus salas, era asimismo otro de los puntos débiles observados, unidos a la deficiente calidad de algunas obras o a lo poco representativo que resultaban ciertas pinturas de Pedro Flores y Garay, empeñados por aquel 1934 en otras aventuras.

D. Pedro Sánchez Picazo se sintió sumamente ofendido y contestó al pintor, que en una contundente respuesta dejó ver la diferencia de mentalidad y, sobre todo, la falta de entendimiento de lo que debe ser un planteamiento museográfico moderno. Se mezcló, desgraciadamente, lo profesional con lo personal. Picazo dio todo un recital de contundentes argumentos en defensa de su propia pintura y de la de Alejandro Séiquer, pero el mundo había cambiado y Picazo no lo había percibido. Acaso, la falta de una puesta al día, la ausencia de criterios claros, jerarquizadores y de comprensión de los verdaderos objetivos de un museo, sean las verdadera razones que alentaron la crítica, no el ataque, dirigido por Gaya al Museo de Murcia o, más en concreto, a la figura de su director al que profesaba verdadero afecto 41 .

Dibujo sentimental fue el nombre dado al Lazo de retorno $I V$, en que reflejó sus impresiones de las calles y de los pueblos de Murcia, de los perros de camioneta, impasibles, habilidosos como equilibristas que sortean todos los peligros de los vai-

\footnotetext{
${ }^{41}$ La respuesta de Ramón Gaya a la defensa que de sí mismo hizo Sánchez Picazo sirve para comprobar el prestigio alcanzado por el pintor murciano, de cuya obra se había hecho eco, ya por aquellos años, Juan Ramón Jiménez, Corpus Barga, Christian Zervos y Sebastián Gasch en páginas de periódicos o en revistas especializadas. Véase en las Obras Completas citadas Respuesta al Señor Picazo, pp. 687-688.
} 
venes de viejos y destartalados vehículos. El lento discurrir de la vida en Murcia como una siesta lenta, con un ritmo de tartana había desaparecido, sustituido por bar y chófer y por perros subidos al techo de las camionetas, sometidos a un peligro vanidoso. Fueron gentes cuyos encantos residían en calmas, en sueños difusos, ahora embrutecidos por la civilización. Acaso, el Museo de Murcia pertenecía a ese mundo de siesta lenta.

El Ángel fue el argumento del Lazo de retorno $V$, momento propicio ante el recuerdo del de Salzillo para introducir una bella reflexión sobre esos seres inmateriales que sienten la pena con el alma, no con el corazón, los que contemplan la muerte en calma, los que no pudieron detener su paso ni pudieron dedicar a Cristo muerto sus alas desnudas. Esa introducción precedía a una sutil reflexión sobre los ángeles de El Greco (ángeles tan altos que nadie supo nunca llegar hasta sus vidas), de Fray Angélico (tiernos y transparentes, de corazón azul) y Miguel Ángel (los más cercanos al mundo).

En la crucifixión de El Greco (Museo Nacional del Prado), siendo los ángeles los más apasionados, iqué indiferentes, qué distraídos del dolor cuando todo parece que se rompe y cae, cuando todo parece que va a zozobrar, a convertirse en un volcán de llagas!

Pero el ángel de su suelo es el Ángel de Salzillo, más que el de la Oración es un ángel huertano. Pequeño y simple, parece que viene de la huerta a ser ángel. En vez de ser ángel de siempre, como los demás. Tiembla la timidez. Pero ha puesto tal inocencia, tal cariño en su falsedad, que está a punto de ser.

No fue. Vive en la huerta, debajo de cada techo, y eso hace que no sea, porque un retrato debe matar al retratado, y, a ti, ángel de Salzillo, te sobrevivió el modelo.

$Y$ ya ves, un ángel puede ser todo lo que traspase la verdad. Por eso en Las Meninas nosotros vemos dos ángeles que reverencian a la infanta niña inclinados. $Y$ esa muchacha que asoma su cabello de paja a la derecha de las Hilanderas ¿No es un ángel también? ¿Y no es eso el arte, convertir las cosas todas en ángeles eternos?

Dibujo sentimental de Rosales dio título al Lazo de retorno VI. La presencia de Rosales en Murcia, recordada a través de su obra en el Museo de Murcia, fue calificada por Gaya como un intento de alargar la muerte. Los cuadros del pintor durante su estancia murciana para escapar de la tuberculosis le llevaron a buscar los aires sanos de la Fuensanta, donde pintó naranjos, huertanos, novillos, un burro atado, es decir, según Gaya, Rosales pintó un poco Murcia, sólo astillas, porque como todo gran pintor es del torso de donde saca esos cuadros, pedacitos de Murcia, entregados al lienzo a la par que su vida.

Las alabanzas a Rosales quedaron mezcladas con sus propias dudas, con lo que será y teme no ser, pensando en un porvenir imposible de alcanzar. Esa posibilidad le angustia y le sugiere esa similitud con un Rosales al que imagina, encaramado a un olivar, asomado a Murcia por alargar la muerte.

Entrar en un museo - aseguraba Gaya - es vestirse de un extraño traje, de un aire especial, de un fresco encerrado. Museo es buhardilla limpia, desván de lujo. Pero cerremos los sentidos, porque aqui están las obras. 